\title{
Decreased gastric tone and delayed gastric emptying precede neutrophil infiltration and mucosal lesion formation in indomethacin- induced gastric damage in rats
}

M.H.L.P. Souza ${ }^{1}$, L.E.A. Troncon ${ }^{1}$, F.Q. Cunha ${ }^{2}$ and R.B. Oliveira ${ }^{1}$
Departamentos de ${ }^{1}$ Clínica Médica and ${ }^{2}$ Farmacologia, Faculdade de Medicina de Ribeirão Preto, Universidade de São Paulo, Ribeirão Preto, SP, Brasil

\section{Correspondence}

R.B. Oliveira

Departamento de Clínica Médica

Hospital das Clínicas, FMRP, USP

Av. Bandeirantes, 3900

14048-900 Ribeirão Preto, SP

Brasil

Fax: +55-16-633-6695.

E-mail: rbdolive@fmrp.usp.br

Research supported by FAPESP and PRONEX.

Received September 20, 2002 Accepted June 23, 2003

\section{Abstract}

Gastric antral dysmotility has been implicated in the pathogenesis of indomethacin-induced gastric damage, but the relationship between gastric motor abnormalities and mucosal lesions has not been extensively studied. We investigated whether changes in gastric tone and gastric retention correlate with mucosal lesions and neutrophil migration in indomethacin-induced gastric damage in rats. Indomethacin, either 5 or $20 \mathrm{mg} / \mathrm{kg}$ (INDO-5 and INDO-20), was instilled into the stomach, and then gastric damage, neutrophil migration, gastric tone and gastric retention were assessed 1 or $3 \mathrm{~h}$ later. Gastric damage was calculated as the sum of the lengths of all mucosal lesions, and neutrophil migration was measured by assaying myeloperoxidase activity. Gastric tone was determined by a plethysmometric method, and gastric retention of either saline or Sustacal ${ }^{\circledR}$ was evaluated by a scintigraphic method. Gastric damage was detectable $3 \mathrm{~h}$ after either INDO-5 or INDO-20, but not after $1 \mathrm{~h}$. Neutrophil migration was significantly higher $3 \mathrm{~h}$ after INDO-20 as compared with INDO-5 or control group, but not after $1 \mathrm{~h}$. Values of gastric tone 1 and $3 \mathrm{~h}$ after either INDO-5 $(1 \mathrm{~h}=1.73 \pm 0.07 \mathrm{ml} ; 3 \mathrm{~h}=1.87$ $\pm 0.03 \mathrm{ml})$ or INDO-20 $(1 \mathrm{~h}=1.70 \pm 0.02 \mathrm{ml} ; 3 \mathrm{~h}=1.79 \pm 0.03 \mathrm{ml})$ were significantly lower than in controls $(1 \mathrm{~h}=1.48 \pm 0.05 \mathrm{ml} ; 3 \mathrm{~h}=1.60 \pm$ $0.06 \mathrm{ml})$. Gastric retention of saline was higher $1 \mathrm{~h}$ after INDO-5 (58.9 \pm $3.3 \%)$ or INDO-20 $(56.1 \pm 3.1 \%)$ compared to control $(45.5 \pm 1.7 \%)$, but not after $3 \mathrm{~h}$. There were no differences concerning gastric retention of Sustacal ${ }^{\circledR}$ between the various groups. Indomethacin induced decreased gastric tone and delayed gastric emptying, which precede mucosal lesion and neutrophil infiltration. These results indicate that there is no relationship between these gastric motor abnormalities and mucosal lesion in indomethacin-induced gastropathy.

\section{Introduction}

Nonsteroidal anti-inflammatory drugs (NSAIDs) are among the most widely used drugs in the world (1). NSAID-induced gastric damage is the major side effect of this
Key words

- Gastric emptying

- Gastric tone

- Indomethacin

- Gastric damage
- Neutrophil type of drug. The mechanism of NSAIDinduced gastric damage is generally believed to be related to the ability of these agents to inhibit gastric prostaglandin generation (1). However, evidence has been recently produced that leukocyte adherence to the vascu- 
lar endothelium (2-4), microcirculatory disturbances, superoxide radicals and protease liberation may be relevant pathogenic mechanisms in NSAID gastropathy $(5,6)$.

Several studies have shown that NSAIDs are associated with altered gastroduodenal motility (6-10). Some data indicate that the administration of NSAIDs is followed by either increased gastric contractility, which correlates with gastric damage (6-9) or decreased intestinal spiking amplitude and disruption of migrating motor complexes (10), with no correlation with gastric damage. More recently, Bassotti et al. (11) showed that gastric antral motility is unchanged after NSAID administration in humans. It follows that the relationship between disturbed gastric motor activity and the extent of NSAIDinduced gastric damage remains controversial.

In spite of a number of studies showing different effects of NSAIDs on antral motor activity $(6-9,11)$, the motor function of the proximal stomach and the gastric emptying of liquid meals in indomethacin-induced gastropathy have not been studied extensively. In the present study we determined whether changes in gastric tone and emptying of nutrient or non-nutrient meals correlate with mucosal lesions and neutrophil infiltration in indomethacin-induced gastric damage in rats.

\section{Material and Methods}

\section{Animals}

Male Wistar rats weighing 220-280 g were fasted for 18-24 $\mathrm{h}$ before the experiments. The animals were housed in cages in temperature-controlled rooms and received water and food ad libitum. All animal treatments and surgical procedures were performed in accordance with the Guide for Care and Use of Laboratory Animals, National Institutes of Health, Bethesda, MD, USA.

\section{Drugs}

The drugs used in this study were indomethacin (Prodome Química e Farmacêutica, São Paulo, SP, Brazil), Tris buffer (Merck, São Paulo, SP, Brazil), 3,3',5,5'tetramethylbenzidine (Sigma, St. Louis, MO, USA), hexadecyltrimethylammonium bromide (H-TAB) (Sigma), urethane (Sigma), and Sustacal ${ }^{\circledR}$ (Mead-Johnson Nutritionals, Bristol-Myers Squibb, São Paulo, SP, Brazil).

\section{Induction of gastric damage}

Gastric damage was induced by intragastric instillation of indomethacin (5 or $20 \mathrm{mg}$ / $\mathrm{kg}$, INDO-5 and INDO-20) dissolved in Tris buffer $(1.22 \%$ ethylthiomethane in distilled water $(\mathrm{w} / \mathrm{v}), \mathrm{pH} 8.0)$. The control group received only the vehicle (Tris buffer). Animals were killed 1 or $3 \mathrm{~h}$ later by decapitation and the stomachs rapidly removed, opened by an incision along the greater curvature and pinned out on a wax platform. The hemorrhagic or ulcerative lesions were counted and their lengths measured with an analogical caliper utilizing a magnifying lens. Gastric damage score (lesion index) was then calculated as the sum of the lengths of all linear lesions (12), which was measured by a single observer (M.H.L.P.S.), who was unaware of the treatment given to the animals. Full-thickness pieces of the gastric corpus were then weighed, frozen and stored at $-70^{\circ} \mathrm{C}$ until the assay for myeloperoxidase (MPO) activity.

\section{Gastric myeloperoxidase activity}

The extent of neutrophil accumulation in the gastric mucosa was measured by assaying MPO activity as previously described (13). Briefly, 50 to $100 \mathrm{mg}$ of gastric tissue was homogenized in 2 volumes of ice-cold buffer $\left(0.1 \mathrm{M} \mathrm{NaCl}, 20 \mathrm{mM} \mathrm{NaPO}_{4}, 15 \mathrm{mM}\right.$ NaEDTA), $\mathrm{pH} 4.7$, and centrifuged at $0.8 \mathrm{~g}$ 
for $15 \mathrm{~min}$. The pellet was then subjected to hypotonic lysis $(900 \mu \mathrm{l}$ of $0.2 \% \mathrm{NaCl}$ solution followed $30 \mathrm{~s}$ later by the addition of an equal volume of a solution containing 1.6\% $\mathrm{NaCl}$ and $5 \%$ glucose). After a further centrifugation, the pellet was resuspended in 50 $\mathrm{mM} \mathrm{NaPO}_{4}$ buffer, $\mathrm{pH}$ 5.4, containing $0.5 \%$ $\mathrm{H}-\mathrm{TAB}$ and re-homogenized. The homogenate was then frozen, thawed three times and centrifuged again at $9.3 \mathrm{~g}$ for $15 \mathrm{~min}$ at $4^{\circ} \mathrm{C}$. MPO activity in the resuspended pellet was assayed by measuring the change in absorbance at $450 \mathrm{~nm}$ utilizing tetramethylbenzidine (1.6 mM) and $\mathrm{H}_{2} \mathrm{O}_{2}(0.5 \mathrm{mM})$. Results are reported as the total number of neutrophils by comparing the absorbance of the tissue supernatant with that of rat peritoneal neutrophils processed in the same way. To this end, neutrophil migration was induced in the peritoneum of rats by injecting carrageenin (300 $\mu \mathrm{g} /$ animal). A standard curve relating neutrophil ( $>90 \%$ purity, 12,500 to 195.3 neutrophils $/ 50 \mu \mathrm{l})$ numbers and absorbance was obtained by processing purified neutrophils as described above and assaying for MPO activity.

\section{Gastric volume under a fixed intragastric pressure}

Gastric tone was evaluated by assessing variations of gastric volume under a fixed pressure. After 18-24 h of fasting with free access to water, animals were anesthetized with urethane $(1.2 \mathrm{~g} / \mathrm{kg}$, ip $)$ and submitted to a tracheotomy to assure free breathing. A balloon catheter made of fingertips of surgical gloves was introduced per os and positioned in the rat proximal stomach, as previously described (14). The opposite end of the catheter was connected to a three-way valve and then to the bottom of a U-shaped glass reservoir equipped with an electronic volume sensor coupled to a plethysmometer (model 7140, Ugo Basile, Varese, Italy). In all experiments, the liquid reservoir level was $4 \mathrm{~cm}$ above the animal xiphoid appen- dix. Since the total volume of fluid in the entire system (stomach plus external reservoir) was known, changes in the volume in the external reservoir reflected those of the stomach. Gastric volume values (in $\mathrm{ml}$ ) were monitored and recorded every minute. After a 10-min period for stabilization of gastric motility, the accuracy of the gastric volume measured with the plethysmometer was assessed in a group of four animals. A preweighed 1-ml syringe was used to gradually change the balloon volume by either injecting into or withdrawing ionic solution aliquots (0.1 ml) from the system up to $\pm 0.5 \mathrm{ml}$. A strong correlation $\left(\mathrm{r}^{2}=0.99\right)$ was observed between the graded balloon volume and the values displayed by the plethysmometer for both injection and withdrawal of the ionic solution. Because of its volumetric capacity, the reservoir functions as a barostat, detecting changes in stomach volume under a constant pressure (14).

Three other groups of rats were treated at random with Tris buffer $(1.22 \%$ ethylthiomethane in distilled water $(\mathrm{w} / \mathrm{v}), \mathrm{pH} 8.0)$, INDO-5, or INDO-20 as described before. One or $3 \mathrm{~h}$ after the injections, gastric volume was measured every minute for $10 \mathrm{~min}$, as described before.

\section{Gastric emptying}

Gastric emptying was assessed by determining the fractional radioactivity remaining in the stomach after intragastric instillation of either saline or Sustacal ${ }^{\circledR}(1.0 \mathrm{ml} / 100$ $\mathrm{mg}$ ) labeled with $10 \mathrm{MBq}$ of ${ }^{99 \mathrm{~m}}$ technetium (Instituto de Pesquisas em Energia Nuclear, IPEN, São Paulo, SP, Brazil) coupled to phytate ("Phytosid", Sydma Medical Reagents and Equipment, Ribeirão Preto, SP, Brazil) as an unabsorbable carrier. Three groups of 6-12 rats each were treated at random with Tris buffer, INDO-5 or INDO20 , as described before. One hour or $3 \mathrm{~h}$ after these injections, the animals were lightly anesthetized with ether and treated at ran- 
Figure 1. Gastric mucosal damage in rats treated with 5 or 20 $\mathrm{mg} / \mathrm{kg}$ indomethacin (INDO-5 or INDO-20) or vehicle (control). After $1 \mathrm{~h}$ (panel A) or $3 \mathrm{~h}$ (panel B), animals were killed and the lesion index $(\mathrm{mm})$ was calculated. Data are reported as the mean \pm SEM for $N=5$. ${ }^{*} \mathrm{P}<0.05 \mathrm{com}-$ pared to control (ANOVA followed by Newman-Keuls test).

Figure 2. Recruitment of neutrophils in the stomach, measured by a myeloperoxidase (MPO) activity assay, in rats treated with 5 or $20 \mathrm{mg} / \mathrm{kg}$ indomethacin (INDO-5 or INDO-20) or vehicle (control). After $1 \mathrm{~h}$ (panel A) or $3 \mathrm{~h}$ (panel B), animals were killed and samples from the gastric mucosa were weighed, frozen and stored at $-70^{\circ} \mathrm{C}$ until time of the MPO activity assay. Results are presented as number of neutrophils per mg tissue and reported as mean \pm SEM for $\mathrm{N}=5$. ${ }^{*} \mathrm{P}<0.01$ compared to control (ANOVA followed by Newman-Keuls test). dom with saline or Sustacal ${ }^{\circledR}$ dissolved in water (32 mg protein, $93.75 \mathrm{mg}$ carbohydrate and $1.75 \mathrm{mg}$ fat). Test meals were administered by gavage, which was followed by immediate removal of the tube. One or $3 \mathrm{~h}$ after these injections, saline or Sustacal ${ }^{\circledR}$ dissolved in water ( $32 \mathrm{mg}$ protein, $93.75 \mathrm{mg}$ carbohydrate and $1.75 \mathrm{mg}$ fat) was instilled
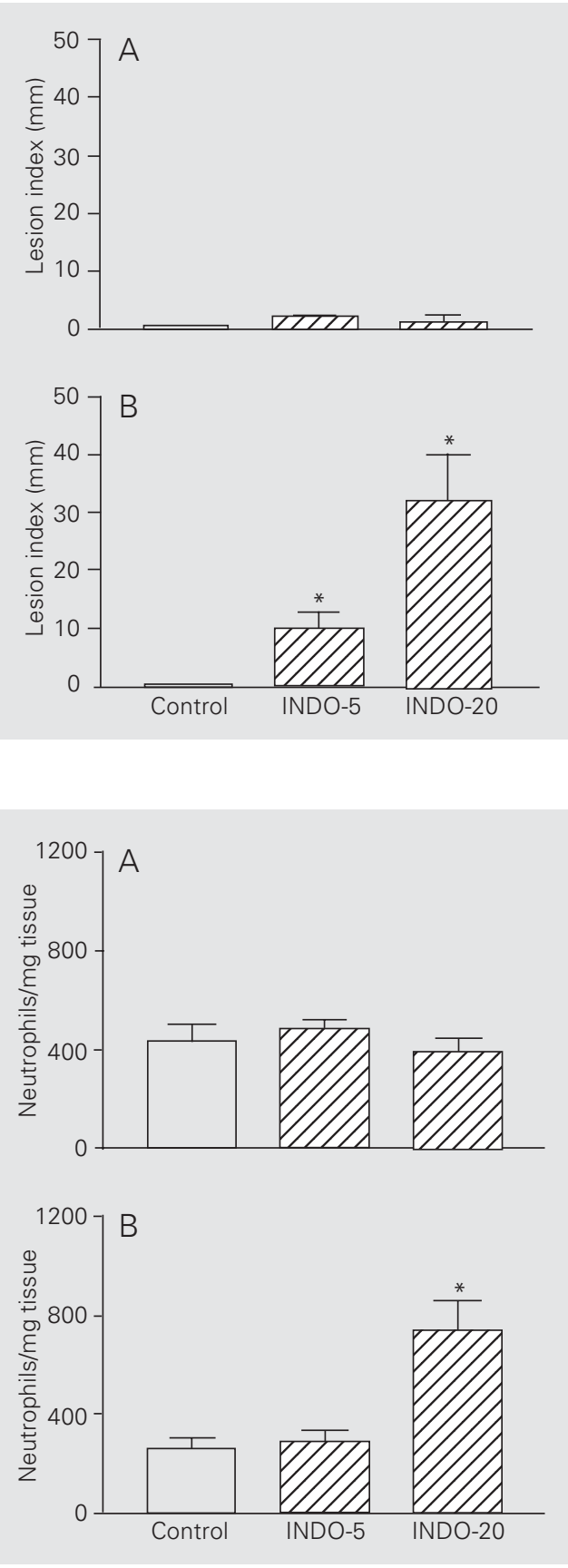

quickly by gavage, with immediate removal of the tube. Thirty minutes after saline administration, or $2 \mathrm{~h}$ after Sustacal ${ }^{\circledR}$ administration, animals were killed by decapitation and the stomach and small and large bowels were isolated by consecutive ligatures at the esophagogastric, gastroduodenal, ileocecal and retosigmoidal junctions. The gut segments were excised and inserted into bags made of glove fingers, where they were kept until counting in order to avoid spillage of their contents. Each segment was counted in a gamma camera (Sopha Vision DST, Sopha Medical Vision America, Twinsburg, OH, USA) and the results are reported as number of counts per minute after subtracting the background activity. The radioactivity remaining in the gastric segment was reported as the percentage of the sum of the counts in all gastrointestinal segments, including the stomach.

\section{Statistical analysis}

Statistical analysis was performed by oneway analysis of variance (ANOVA) followed by the Newman-Keuls test when appropriate, with the level of significance set at $\mathrm{P}<$ 0.05 . The accuracy of gastric volume measurements by plethysmometry was assessed using Pearson's linear regression.

\section{Results}

As shown in Figure 1B, intragastric instillation of both INDO-5 and INDO-20 caused significant $(\mathrm{P}<0.05)$ and dose-dependent gastric damage, $3 \mathrm{~h}$ after drug administration, with maximal effect at the dose of $20 \mathrm{mg} / \mathrm{kg}$. After $1 \mathrm{~h}$, however, indomethacin administration caused negligible gastric damage with either 20 or $5 \mathrm{mg} / \mathrm{kg}$ (Figure 1A).

Figure 2B shows that neutrophil migration in the gastric mucosa was significantly higher $(\mathrm{P}<0.01) 3 \mathrm{~h}$ after INDO-20, as compared with INDO-5 or vehicle (control). 
However, there was no difference in neutrophil migration after $1 \mathrm{~h}$ in the same groups (Figure 2A).

Values of gastric volume $1 \mathrm{~h}$ after either INDO-5 or INDO-20 were significantly higher $(\mathrm{P}<0.01)$ than in controls (Figure $3 \mathrm{~A})$. In addition, $3 \mathrm{~h}$ after indomethacin, gastric volume was significantly higher $(\mathrm{P}<$ $0.01)$ in both INDO-5 and INDO-20 groups as compared with control animals (Figure 3B).

Gastric retention of saline $1 \mathrm{~h}$ after either INDO-5 or INDO-20 was significantly higher $(\mathrm{P}<0.05)$ compared to control (Figure 4A). However, $3 \mathrm{~h}$ after indomethacin, there were no significant differences between INDO-5 or INDO-20 and controls (Figure 4C). There were no differences in the gastric emptying of Sustacal ${ }^{\circledR}$ between the various groups either $1 \mathrm{~h}$ (Figure 4B) or $3 \mathrm{~h}$ after indomethacin administration (Figure 4D).

\section{Discussion}

The role of disturbances of gastric motility in the pathogenesis of NSAID-induced gastric damage remains to be elucidated.
Takeuchi et al. $(8,9)$ reported increased amplitude of antral contractions in indomethacin-induced gastric lesions in rats and suggested that gastric hypercontractility could play an important role in the pathogenesis of this condition. However, Fioramonti and Bueno (10) showed that indomethacin-induced gastric ulceration was associated with

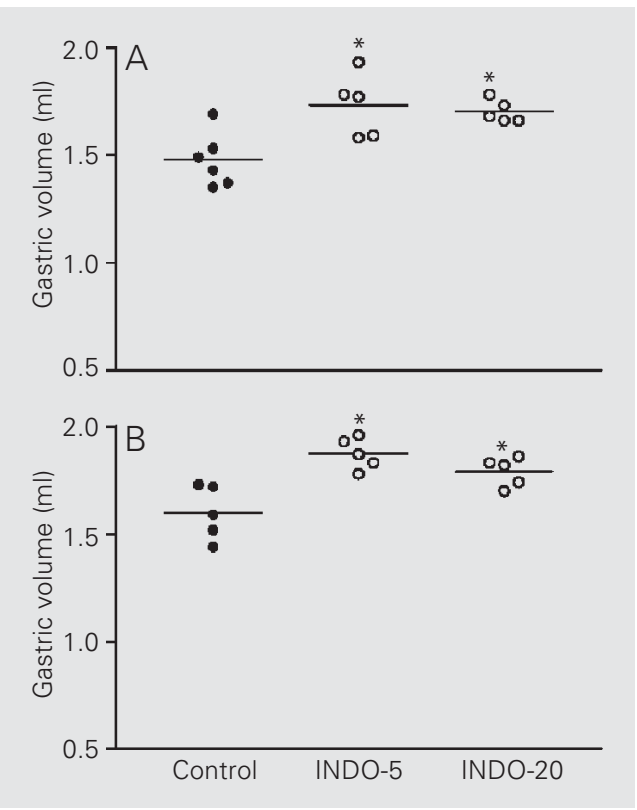

Figure 3. Gastric tone (volumes measured under a fixed intragastric pressure) in rats treated with 5 or $20 \mathrm{mg} / \mathrm{kg}$ indomethacin (INDO-5 or INDO-20) or control rats injected with Tris buffer. Measurements were started $1 \mathrm{~h}$ (panel A) or $3 \mathrm{~h}$ (panel B) after indomethacin administration. Data are individual values of gastric volume (in $\mathrm{ml}$ ) recorded by plethysmography in anesthetized rats. The individual values were pooled into 10-min intervals. The horizontal bars represent the means. ${ }^{*} P<0.01$ compared to control (ANOVA followed by Newman-Keuls test).
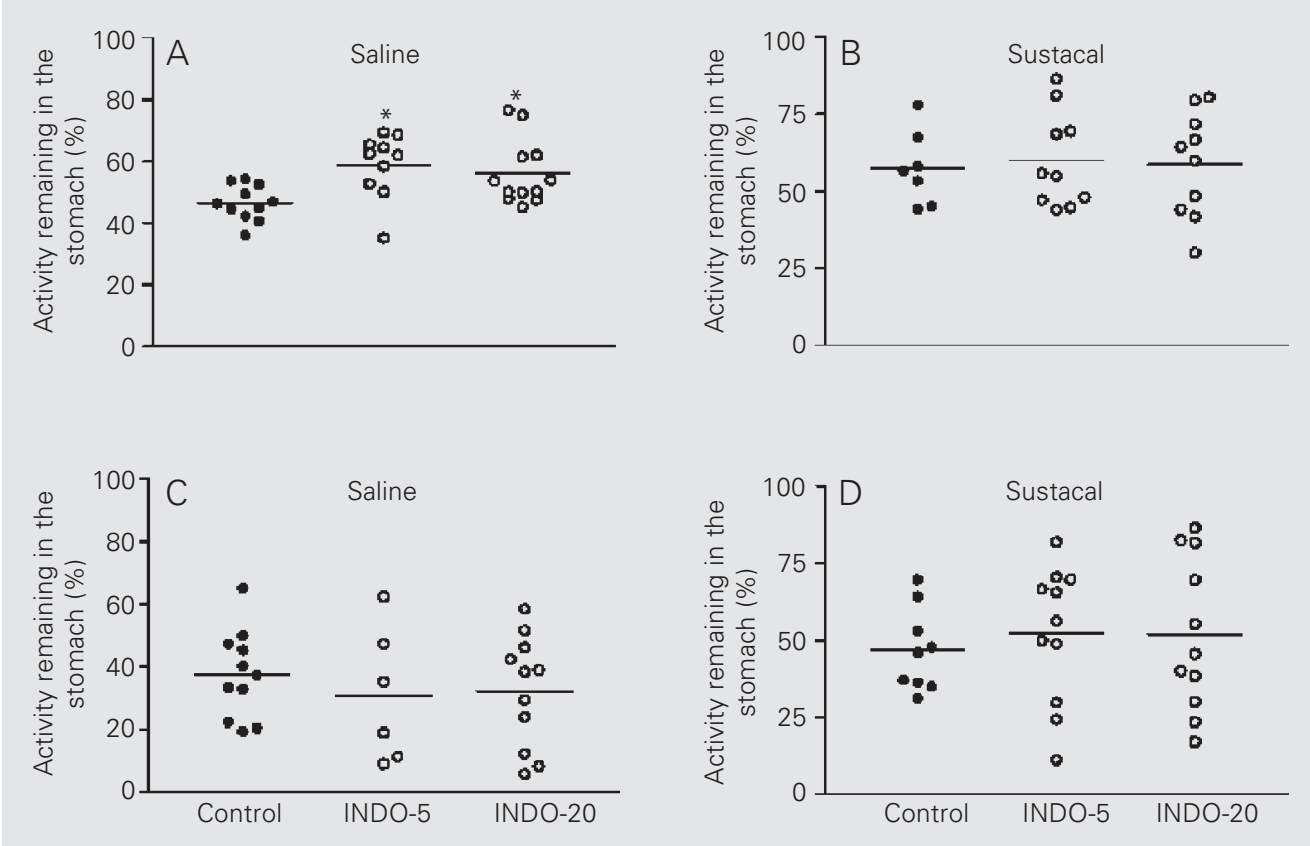

Figure 4. Gastric emptying of saline (panels A and C) or Susta$\mathrm{cal}^{\circledR}$ (panels B and D) in rats treated with 5 or $20 \mathrm{mg} / \mathrm{kg}$ indomethacin (INDO-5 or INDO$20)$ or control rats injected with Tris buffer. The studies started $1 \mathrm{~h}$ (panels $\mathrm{A}$ and $\mathrm{B}$ ) or $3 \mathrm{~h}$ (panels $C$ and $D$ ) after indomethacin administration. Data are individual values of the radioactivity remaining in the stomach $30 \mathrm{~min}$ after saline administration or $2 \mathrm{~h}$ after Sustacal ${ }^{\circledR}$ administration. Meals were labeled with $99 m_{\text {technetium coupled to }}$ phytate as an unabsorbable carrier. Results are reported as percent of the total activity in the gastrointestinal tract. Horizontal bars indicate the means. ${ }^{*} \mathrm{P}<$ 0.05 compared to control (ANOVA followed by NewmanKeuls test). 
both a reduction of intestinal spiking amplitude and disruption of the migrating motor complexes, but these motor abnormalities did not correlate with the extent of gastric mucosal damage. More recently, Bassotti et al. (11) were not able to show any difference in gastric antral motility after NSAID administration in men. In the present study we investigated whether changes in gastric motility concerning the proximal stomach and gastric emptying of liquid meals correlated with mucosal lesions and neutrophil infiltration in indomethacin-induced gastric damage and we found that decreased gastric tone and delayed emptying precede but do not seem to correlate with inflammatory and erosive changes in the gastric mucosa induced by indomethacin.

Our results indicate that neutrophil infiltration and gastric erosions were dose-dependent and evident $3 \mathrm{~h}$, but not $1 \mathrm{~h}$, after indomethacin administration, which is consistent with other studies showing that indomethacin caused a dose- and time-dependent increase in the extent of gastric mucosal damage and tissue MPO activity $(8,15)$. Trevethick et al. (15) showed that the ulceration became first apparent macroscopically $2 \mathrm{~h}$ after dosing with indomethacin, and Takeuchi et al. (8) observed hemorrhagic lesions only within $4 \mathrm{~h}$ after indomethacin administration. Also, in our study, neutrophil migration was detected only with the higher dose $(20 \mathrm{mg} / \mathrm{kg})$, but not with the lower dose of indomethacin $(5 \mathrm{mg} / \mathrm{kg})$, which conflicts with the result of another study showing that administration of $5 \mathrm{mg} / \mathrm{kg}$ indomethacin caused an increase in MPO activity (4). This discrepancy could be ascribed to the differences in the sensitivity of the MPO assay used. However, we cannot rule out the possibility that in our study the gastric damage induced by low doses of indomethacin was a neutrophil-dependent process.

The results of the present study also showed that indomethacin administration caused a reduction in gastric fundus tone, expressed as an increased gastric intraballoon volume with a fixed pressure at all times and with all doses used. These results are in agreement with previous studies that showed a reduction in gastric tone in vitro by indomethacin pretreatment (16). Studies performed in vitro showed that indomethacin administration can reduce the responsiveness to acetylcholine in both the longitudinal and the circular layers of muscle strips (17). It is noteworthy that a decreased cholinergic reactivity after indomethacin administration could explain our observations. Alternatively, the indomethacin-induced reduction in gastric fundus tone might be explained by an increase in nonadrenergic, noncholinergic relaxation. However, this does not seem to be the case, since Gustafsson and Delbro (18) showed that the vagally induced nonadrenergic, noncholinergic gastric relaxation was significantly reduced in vivo by indomethacin. In addition, Corak et al. (17) showed that indomethacin-induced reduction of responsiveness to acetylcholine in both the longitudinal and the circular layers of muscle strips was not affect by L-NAME pretreatment.

We found a significant delay in the gastric emptying of saline $1 \mathrm{~h}$ after indomethacin, when neither gastric damage nor neutrophil infiltration had yet been detected. Our results suggest that changes in gastric motor activity are not related to macroscopic gastric mucosal damage. Nevertheless, we cannot completely rule out a contribution of motor abnormality in gastric lesion formation, because we did not measure microscopic damage in the early phase. These results agree with previous gastric emptying studies conducted on both rats (17) and in humans (19) showing that the delay in gastric emptying bears no apparent relationship with gastric mucosal damage. In contrast, gastric tone was still decreased by the time both gastric mucosal damage and neutrophil infiltration had become apparent, $3 \mathrm{~h}$ after 
indomethacin administration, but was not associated with delayed gastric emptying of non-nutrient or nutrient meals. Decreased gastric tone, as we consistently found after indomethacin, would theoretically be associated with delayed gastric emptying, which we found with saline only $1 \mathrm{~h}$ after drug administration (Figure 4). This apparent discrepancy between decreased gastric tone and unaltered gastric emptying of saline might be explained by the effect of indomethacin administration on duodenal motility, which was not evaluated in this study. Fioramonti and Bueno (10) reported that decreased amplitude of spike potentials and abolished fasting migrating motor complexes were shown in indomethacin-induced gastric damage. In addition, Lu et al. (20) demonstrated that after indomethacin administration, intestinal segments with lesions failed to produce peristaltic activity, whereas in those segments with no visible lesions the peristaltic activity was enhanced. Concerning gastric emptying of Sustacal ${ }^{\circledR}$, we were not able to find any difference between control and indomethacin-treated animals, at any time point or doses utilized. This could be explained by the strong inhibitor effect of the fat and protein components of Sustacal ${ }^{\circledR}$ on duodenal receptors, which could slow gastric emptying through a variety of motor mechanisms, including decreased gastric tone, and therefore mask any possible effect of indomethacin.
As far as the clinical meaning of our results is concerned, it is noteworthy that at least 10 to $20 \%$ of patients taking NSAIDs have gastric mucosal lesions and upper gastrointestinal symptoms, while the overall prevalence of dyspepsia may reach up to $50 \%$ of patients on NSAIDs $(21,22)$. The mechanisms underlying NSAID-related dyspepsia associated or not with gastric mucosal lesions are poorly understood and current interpretations lack a scientific basis (23). Since our results show the occurrence of motor abnormalities concerning both gastric proximal function and emptying in an animal model of NSAID-induced gastric damage at a time when the animals have not yet developed gastric mucosal damage, it is tempting to speculate whether gastric motor abnormalities play a role in the origin of some symptoms in NSAID-associated dyspepsia. In order to confirm this hypothesis, further studies on humans are needed. Recently, Holtmann et al. (24) showed that a failure to increase sensory thresholds during treatment with aspirin is associated with the development of dyspepsia.

\section{Acknowledgments}

The authors gratefully acknowledge the technical assistance of Marie Secaf, Carlos R. Cambrea, Adalberto Valladas Verceze, Maurício Rodrigues de Arantes, and Roni Charles Fabbris.

\section{References}

1. Vane JR (1971). Inhibition of prostaglandin synthesis as a mechanism of action for aspirin-like drugs. Nature New Biology, 231: 232235.

2. Asako H, Kubes P, Wallace J, Wolf RE \& Granger DN (1992). Modulation of leukocyte adhesion in rat mesenteric venules by aspirin and salicylate. Gastroenterology, 103: 146-152.

3. Asako H, Kubes P, Wallace J, Gaginella T, Wolf RE \& Granger DN (1992). Indomethacin-induced leukocyte adhesion in mesenteric venules: role of lipoxygenase products. American Journal of Physiology, 262: G903-G908.

4. Santucci L, Fiorucci S, Di Matteo FM \& Morelli A (1995). Role of tumor necrosis factor alpha release and leukocyte margination in indomethacin-induced gastric injury in rats. Gastroenterology, 108 : 393-401.

5. Wallace JL (1997). Nonsteroidal anti-inflammatory drugs and gastroenteropathy: the second hundred years. Gastroenterology, 112: 1000-1016

6. Takeuchi K, Takehara K \& Ohuchi T (1996). Diethyldithiocarbamate, a superoxide dismutase inhibitor, reduces indomethacin-induced gastric lesions in rats. Digestion, 57: 201-209.

7. Hawkey CJ (2000). Nonsteroidal anti-inflammatory drug gastropathy. Gastroenterology, 119: 521-535.

8. Takeuchi K, Ueki S \& Okabe S (1986). Importance of gastric motility in the pathogenesis of indomethacin-induced gastric lesions in rats. 
Digestive Diseases and Sciences, 31: 1114-1122.

9. Ueki S, Takeuchi K \& Okabe S (1988). Gastric motility is an important factor in the pathogenesis of indomethacin-induced gastric mucosal lesions in rats. Digestive Diseases and Sciences, 33: 209216.

10. Fioramonti J \& Bueno L (1980). Gastrointestinal myoelectric activity disturbances in gastric-ulcer disease in rats and dogs. Digestive Diseases and Sciences, 25: 575-580.

11. Bassotti G, Bucaneve G, Furno P, Morelli A \& Del Favero A (1998). Double-blind, placebo-controlled study on effects of diclofenac sodium and indomethacin on postprandial gastric motility in man. Digestive Diseases and Sciences, 43: 1172-1176.

12. Santucci L, Fiorucci S, Giansanti M, Brunori PM, Di Matteo FM \& Morelli A (1994). Pentoxifylline prevents indomethacin-induced acute gastric-mucosal damage in rats: role of tumor necrosis factor alpha. Gut, 35: 909-915.

13. Souza DG, Cassali GD, Poole S \& Teixeira MM (2001). Effects of inhibition of PDE4 and TNF- $\alpha$ on local and remote injuries following ischaemia and reperfusion injury. British Journal of Pharmacology, 134: 985-994

14. Graca JRV, Leal PRL, Gondim FA, Rola FH \& Santos AA (2000). A plethysmometric method for gastric compliance studies in anesthetized rats. Journal of Pharmacological and Toxicological Methods, 43: 25-30.

15. Trevethick MA, Clayton NM, Strong P \& Harman IW (1993). Do infiltrating neutrophils contribute to the pathogenesis of indomethacin induced ulceration of the rat gastric antrum? Gut, 34: 156-160.

16. Frankhuijzen AL \& Bonta IL (1975). Role of prostaglandins in tone and effector reactivity of the isolated rat stomach preparation. Euro- pean Journal of Pharmacology, 31: 44-52.

17. Corak A, Coskun T, Alican I, Kurtel H \& Yegen BC (1997). The effect of nitric oxide synthase blockade and indomethacin on gastric emptying and gastric contractility. Pharmacology, 54: 298-304.

18. Gustafsson BI \& Delbro DS (1988). Effects of indomethacin on nonadrenergic, non-cholinergic motility of stomach and small intestine. European Journal of Pharmacology, 147: 67-72.

19. Kulkarni SG, Parikh SS, Shankhpal PD, Desai SA, Borges NE, Desa SB, Vora IM \& Kalro RH (1999). Gastric emptying of solids in longterm NSAID users: correlation with endoscopic findings and Helicobacter pylori status. American Journal of Gastroenterology, 94: 382386

20. Lu YF, Mizutani M, Neya T \& Nakayama S (1995). Indomethacininduced lesion modifies contractile activity in rat small intestines. Scandinavian Journal of Gastroenterology, 30: 445-450.

21. Larkai EN, Smith JL, Lidsky MD \& Graham DY (1987). Gastroduodenal mucosa and dyspeptic symptoms in arthritic patients during chronic nonsteroidal anti-inflammatory drug use. American Journal of Gastroenterology, 82: 1153-1158.

22. Singh G \& Triadafilopoulos G (1999). Epidemiology of NSAID induced gastrointestinal complications. Journal of Rheumatology, 26 (Suppl 56): 18-24.

23. Jones J \& Raud J (2001). Nonsteroidal anti-inflammatory drugassociated dyspepsia: basic mechanisms and future research. American Journal of Medicine, 110: 14S-18S.

24. Holtmann G, Gschossmann J, Buenger L, Gerken G \& Talley NJ (2002). Do changes in visceral sensory function determine the development of dyspepsia during treatment with aspirin? Gastroenterology, 123: 1451-1458. 